income. Unemployment, however, remained a relevant factor as it was frequently the cause of a low income. A trend was found for smoking to be associated with delivery before 37 weeks' gestation. When length of gestation was treated as a continuous variable and possible predictors were examined none was found.

Our study did not replicate previous findings of an association between low birth weight and social class, psychiatric morbidity, or adverse life events and between preterm delivery and adverse life events. ${ }^{1-4}$ The results suggest that low income may well be an important factor underlying the association between social adversity and low birth weight. Whether low income acts as a stressor and whether its effect is mediated by factors such as inadequate maternal nutrition are issues that require further investigation.

We thank the women who participated in the study; Mrs A Bond and Dr $\mathrm{H}$ Kennerley for their help in collecting the data; and the staff of the John Radcliffe Hospital for their help, particularly Mrs P Yudkin, Mrs N Hegarty, and the coding staff of the Oxford obstetric data system. The research was supported by a fellowship to PJC from the Mental Health Foundation and a grant from the Oxford Regional Health Authority; AS was supported by the Wellcome Trust. We thank Dr J Dennis and Dr A Grant for their comments on an earlier draft of this manuscript, and Dr D Gath and Professor M G Gelder for their help and support.

\section{References}

1 Newton RW, Webster PAC, Binu PS, Maskrey N, Phillips AB. Psychological stress in pregnancy and its relation to the onset of premature labour. $\mathrm{Br}$ Med $\mathcal{F}$ 1979;ii:411-3.

2 Newton RW, Hunt PL. Psychosocial stress in pregnancy and its relation to low birth weight. BrMed J 1984;288:1191-4.

3 Berkowitz GS, Kasl SV. The role of psychosocial factors in spontaneous preterm delivery. J Psychosom Res 1983;27:283-90.

4 Norbeck JS, Tilden VP. Life stress, social support and emotional disequilibrium in complications of pregnancy: a prospective, multivariate study. I Health Soc Behav 1983;24:30-46.

of pregnancy: a prospective, multivariate study. F Health Soc Behav 1983,24:

6 Cohler BJ, Gallant DH, Grunebaum HU, Weiss JL, Gamer E. Pregnancy and birth complications among mentally ill and well mothers and their children. Soc Biol 1975;22:269-78.
amoly

$7 \mathrm{Zax}$ M, Sameroff AJ, Babigan HM. Birth outcomes in the offspring of mentally disordered women. Am $\mathcal{F}$ Orhopsychiatry 1977;47:218-30.

8 Wolkind S. Prenatal emotional stress-effects on the foetus. In: Wolkind S, Zajicek E, eds. Pregnancy a psychological and social study. London: Academic Press, 1981:177-94.

9 Paykel ES. Methodological aspects of life events research. J Psychosom Res 1983;27:341-52.

10 Cohen J. Weighted kappa: nominal scale agreement with provision for scaled disagreement or partial credit. Psychol Bull 1968;70:213-20.

11 Wing JK, Cooper JE, Sartorius N. The measurement and classification of psychiatric symptoms. Cambridge: Cambridge University Press, 1974.

12 Wing JK, Cooper JE, Sartorius N. An insenuction mamual for the present state examination and CATEGO program. Cambridge: Cambridge University Press, 1974.

13 Goldthorpe $\mathrm{JH}$, Hope $\mathrm{K}$. The social grading of occupations: a new approach and scale. Oxford: Clarendon Press, 1974 .

14 McCullagh P, Nelder JA. Generalised linear models. London: Chapman and Hall, 1984

15 Dunn HG. Social aspects of low birth weight. Can Med Assoc $\mathcal{f}$ 1984;130:1131-40.

16 Fedrick J, Anderson ABM. Factors associated with spontaneous pre-term birth. $\mathrm{Br} \mathcal{F}$ Obstet Gynaecol 1976;83:342-50.

\title{
Lymphocyte transformation response to pokeweed mitogen as a predictive marker for development of AIDS and AIDS related symptoms in homosexual men with HIV antibodies
}

\author{
BO HOFMANN, BJARNE ØRSKOV LINDHARDT, JAN GERSTOFT, \\ CARSTEN SAND PETERSEN, PER PLATZ, LARS P RYDER, NIELS ØDUM, \\ EBBE DICKMEISS, PEDER BO NIELSEN, SUSANNE ULLMAN, ARNE SVEJGAARD
}

\begin{abstract}
To identify factors that may predict the development of the acquired immune deficiency syndrome (AIDS) or AIDS related symptoms various immunological measurements were studied in a group of homosexual men attending screening clinics for AIDS
\end{abstract}

State University Hospital, Copenhagen, Denmark

BO HOFMANN, MD, research fellow, tissue typing laboratory, department of clinical immunology

BJARNE ØRSKOV LINDHARDT, MD, research fellow, department of infectious diseases and laboratory of tumour virology, Fibiger Institute

PER PLATZ, MD, senior registrar, tissue typing laboratory, department of clinical immunology

LARS P RYDER, MSC, biochemist, tissue typing laboratory, department of clinical immunology

NIELS ØDUM, MD, research fellow, tissue typing laboratory, department of clinical immunology

EBBE DICKMEISS, $M D$, senior registrar, tissue typing laboratory, department of clinical immunology

SUSANNE ULLMAN, $M D$, head, department of venereal diseases

ARNE SVEJGAARD, MD, DSCI, head, tissue typing laboratory, department of clinical immunology

State Serum Institute, Copenhagen, Denmark

JAN GERSTOFT, MD, senior registrar, rubella department

PEDER BO NIELSEN, MD, senior registrar, diagnostic department

Department of Dermato-Venereology, Bispebjerg Hospital, Copenhagen, Denmark

CARSTEN SAND PETERSEN, MD, senior registrar

Correspondence to: Dr B Hofmann, Tissue Typing Laboratory, Division 7631, State University Hospital (Rigshospitalet), Copenhagen 2200N, Denmark. in Copenhagen. Fifty seven men whose ratio of $T$ helper lymphocytes to $T$ suppressor lymphocytes (CD4:CD8 ratio) was less than 1.0 before the study began were included. Forty two were positive for antibody to the human immunodeficiency virus (HIV), of whom 38 were reinvestigated after a median observation period of 10 months. Among the seropositive men the transformation responses to pokeweed mitogen and cytomegalovirus and the absolute count of CD4 positive lymphocytes were the most common abnormal values. In particular, a low relative response to pokeweed mitogen on initial investigation correlated with a worsened clinical condition on reinvestigation. The risk of a worsened clinical condition was 55 times higher in seropositive men whose responses to pokeweed mitogen were low than in other seropositive men. The corresponding relative risks for low transformation responses to cytomegalovirus and for a decreased absolute count of CD4 positive lymphocytes were 18 and six.

The relative response to pokeweed mitogen is therefore a very sensitive short term predictive marker of the clinical condition of seropositive patients who have a CD4:CD8 ratio of less than 1.0.

\section{Introduction}

Though the presence of antibodies to the human immunodeficiency virus (HIV) is an important measurement in epidemiological studies of the acquired immune deficiency syndrome (AIDS), the predictive value of a positive antibody test is low as $80-95 \%$ of seropositive patients remain healthy for at least several years after they become infected..$^{1-3}$ Various immunological tests have been used to try to predict the prognosis of people positive for HIV antibody. ${ }^{45}$ Thus the absolute count of T helper (CD4 positive) lymphocytes and the 
ratio of $T$ helper lymphocytes to $T$ suppressor lymphocytes (CD4:CD8 ratio) have been reported to be useful predictors of the development of symptoms associated with HIV in seropositive patients. ${ }^{6-8}$ To allow patients to be counselled, however, the accuracy of the prediction must be extremely high.

We aimed to clarify the value of the transformation responses of lymphocytes to mitogens and antigens and the value of lymphocyte subsets in predicting the clinical course of disease in patients who were positive for antibodies to HIV and who had CD4:CD8 ratios of less than $1 \cdot 0$.

\section{Subjects and methods}

\section{PATIENTS}

Fifty seven homosexual men who attended screening clinics for AIDS in Copenhagen from June 1984 to February 1985 were selected because their CD4:CD8 ratio had been less than 1.0 in a prescreening session one month earlier, and they underwent further immunological investigation. During the investigation four men died from AIDS. The $\mathbf{4 0}$ survivors were followed up for a median of 10 (range four to 19) months after the initial investigation.

The median age of the subjects at the initial investigation was 35 (range 2056). At both investigations all the men were clinically classified as being asymptomatic, being asymptomatic and having lymphadenopathy, having lymphadenopathy and B symptoms, or having AIDS related complex or AIDS (Centers for Disease Control criteria). The B symptoms included fever, weight loss ( $>10 \%$ of body weight), and night sweat (Walter-Reed). ${ }^{9}$

\section{ISOLATION OF LYMPHOCYTES AND CULTURE TECHNIQUES}

Peripheral blood mononuclear cells were isolated by Lymphoprep density gradient centrifugation (Nyegaard and Co, Oslo, Norway). Cultures were prepared in triplicate in $0.35 \mathrm{ml}$ round bottom plastic microtitre plates (Greiner, Nurtingen, West Germany). Each culture contained 50000 peripheral blood mononuclear cells in $150 \mu$ l RPMI 1640 medium (Gibco, New York, United States) supplemented with antibiotics, heparin, L-glutamine, and $10 \%$ heat inactivated pooled human male serum).

The amount of mitogen added per well was phytohaemagglutinin (Difco, Detroit, United States) $20 \mu \mathrm{g}$, con A (Pharmacia, Uppsala, Sweden) $10 \mu \mathrm{g}$, or pokeweed mitogen (Gibco) $20 \mu \mathrm{l}$ 1:50 suspension. The amount of antigen added was $20 \mu \mathrm{l}$ of a solution containing, cytomegalovirus 1:4, Pneumocystis carinii 1:50, herpes simplex 1:100, Candida albicans 1:10, tetanus toxin 1:50, or purified protein derivative 1:100.

Tritium labelled thymidine $(1 \mu \mathrm{Ci})$ was added to all cultures that contained mitogens after 72 hours and to cultures that contained antigens after 96 hours. After a further 24 hours the cells were collected on glassfibre filters with an automatic harvesting machine (Skatron, Lierbyen, Norway), and the incorporated radioactivity. was measured with a liquid scintillation counter (Beckman LS 1800) after.1.5 ml scintillation fluid had been added.

The results are given as the medians of the triplicate determinations. The responses to mitogens were expressed as percentages of the responses of two healthy controls investigated simultaneously, and the responses to antigens were taken as the counts per minute (cpm).

\section{LYMPHOCYTE SUBSETS}

The peripheral blood mononuclear cells were investigated on a fluorescence activated cell sorter analyser (Becton Dickinson, California, United States) with monoclonal antibodies conjugated with biotin (Leul (CD5), Leu2 (CD8), Leu3 (CD4), Leu11 (CD16), HLA-DR, poly Ig; Becton Dickinson) and avidin conjugated with fluorescein isothiocyanate (Vector, California, United States).

The total lymphocyte count and the differential count were determined by conventional methods.

\section{HIV ANTIBODY DETERMINATION}

Antibodies to HIV were detected with an enzyme linked immunosorbent assay (ELISA), and positive samples were confirmed by Western blot analysis. ${ }^{10} 11$

\section{STATISTICAL METHODS}

Figure 1 shows the probability plot used. Fisher's exact test and the two tailed Mann-Whitney U test were used to compare the groups.

\section{Results}

Of the 57 men who underwent the extended immunological investigation, 42 were positive for antibodies to HIV. At clinical investigation the 15 seronegative men were asymptomatic except for two who had acute hepatitis. Of the 42 seropositive men, 18 were asymptomatic, 15 had

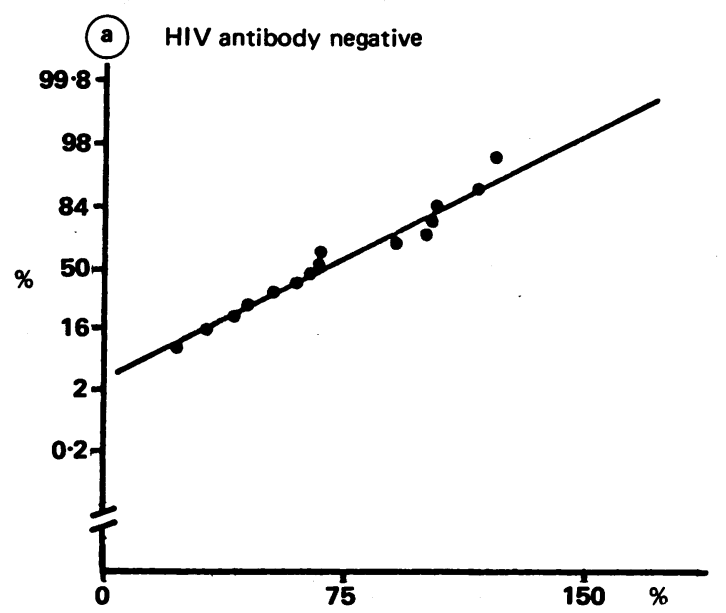

(b) HIV antibody positive

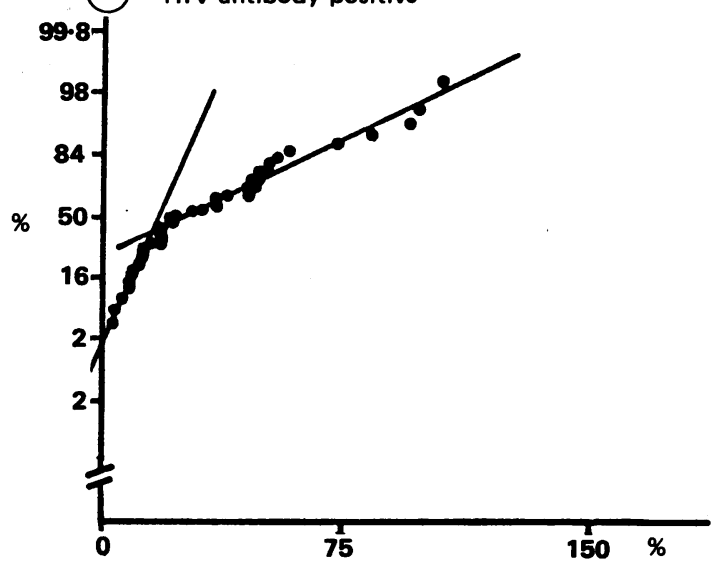

(C) HIV antibody positive

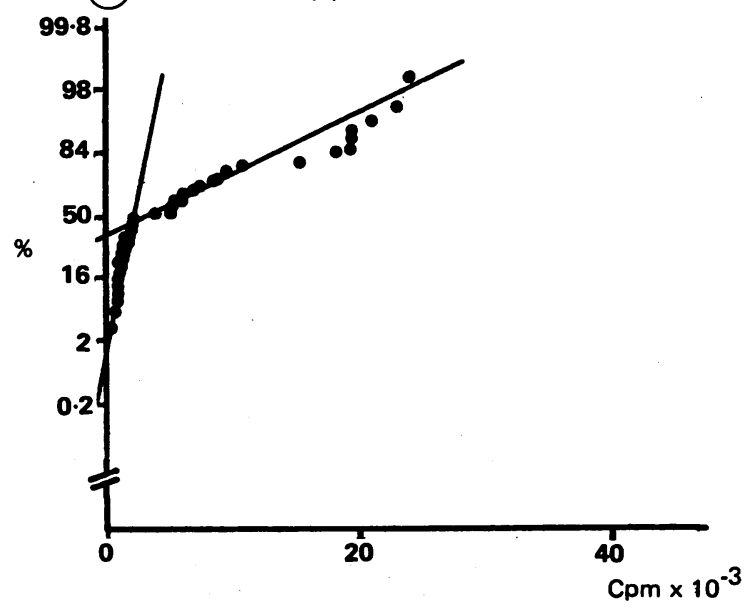

FIG 1-Probability plot of: (a) relative transformation responses to pokeweed mitogen in HIV seronegative men; (b) relative transformation responses to pokeweed mitogen in HIV seropositive men; and (c) absolute responses to cytomegalovirus in HIV seropositive men. Cut off points for positive responses to pokeweed mitogen and cytomegalovirus in HIV seropositive men are indicated by intersecting lines. (One value missing in (b) and (c) for patients negative for HIV antibody.) 
lymphadenopathy, four had lymphadenopathy and B symptoms, two had AIDS related complex, and two had AIDS.

At clinical follow up one year after the initial investigation six of the 15 seronegative men were reinvestigated, and all were found to be seronegative and asymptomatic. Of the $\mathbf{4 2}$ seropositive men, 38 were re-examined; nine were asymptomatic, 14 had lymphadenopathy, four had AIDS related complex, seven had AIDS, and four had died from AIDS. At this second investigation the clinical condition of two men had improved, 18 men were clinically unchanged, and 18 were in a worse clinical condition. The two men who were suffering from AIDS at the first examination had both died.

About one month after the first screening those who had been included in the study because their CD4:CD8 ratio was less than 1.0 were immunologically reinvestigated. Table I summarises some of the immunological data. On examination, the ratios had returned to normal in several men, and significantly higher ratios were found in seronegative men (median ratio $1 \cdot 1$, range $0 \cdot 4-2 \cdot 3$ ) than in seropositive men (median ratio $0 \cdot 48$, range $0 \cdot 01-2 \cdot 2$ ) $(\mathrm{p}<0.0006$, Mann-Whitney $\mathrm{U}$ test). The most common abnormal immunological values among both seropositive and seronegative men were the transformation responses to pokeweed mitogen and cytomegalovirus and the absolute count of CD4 positive lymphocytes. These variables were used in the following analysis.

TABLE I-Initial immunological data on 57 homosexual men in study. Values are medians (ranges)

\begin{tabular}{llcl}
\hline \multicolumn{1}{c}{ Immune response } & $\begin{array}{c}\text { Seropositive } \\
(\mathrm{n}=42)\end{array}$ & $\begin{array}{c}\text { Seronegative } \\
(\mathrm{n}=15)\end{array}$ & Significance \\
\hline Phytohaemagglutinin (\% of controls) & $64(3-171)$ & $99(68-156)$ & $\mathrm{p}=0.0006$ \\
Con A (\% of controls) & $66(1-141)$ & $102(51-167)$ & $\mathrm{p}=0.0006$ \\
Pokeweed mitogen (\% of controls) & $28(4-110)$ & $68(23-189)$ & $\mathrm{p}=0.00022$ \\
Candida albicans (cpm $\left.\times 10^{-3}\right)$ & $10 \cdot 3(0 \cdot 8-111 \cdot 5)$ & $33 \cdot 2(1 \cdot 1-100 \cdot 2)$ & $\mathrm{p}=0.0046$ \\
Cytomegalovirus (cpm $\left.\times 10^{-3}\right)$ & $2 \cdot 2(0 \cdot 4-26 \cdot 2)$ & $9 \cdot 6(0 \cdot 5-38 \cdot 2)$ & $\mathrm{p}=0.040$ \\
CD8 (\%) & $45(17-75)$ & $32(10-54)$ & $\mathrm{p}=0.096$ \\
CD4 (\%) & $21(1-54)$ & $31(19-49)$ & $\mathrm{p}=0.0014$ \\
CD4 (absolute counts) & $0 \cdot 6(0 \cdot 1-1 \cdot 3)$ & $1 \cdot 1(0 \cdot 4-2 \cdot 5)$ & $\mathrm{p}=0.26$ \\
CD4:CD8 ratio & $0 \cdot 48(0 \cdot 01-2 \cdot 2)$ & $1 \cdot 1(0 \cdot 4-2 \cdot 3)$ & $\mathrm{p}=0.006$ \\
\hline
\end{tabular}

${ }^{\star}$ Mann-Whitney U test.

TABLE II-Correlation between initial immunological data and clinical course in 34 men positive for antibodies to HIV and without AIDS or AIDS related complex

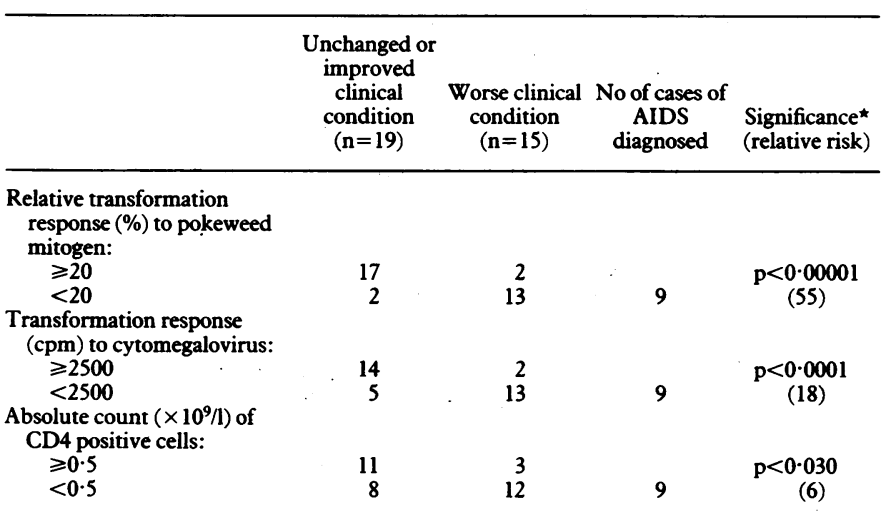

^Fisher's exact test.

A probability plot was used to discriminate between "non-responders" and "responders" in lymphocyte transformation. As figure 1 shows, the relative transformation responses to pokeweed mitogen in seronegative men gave a straight line, while the responses of the seropositive men gave two straight lines intersecting at a relative response of $20 \%$, indicating that the responses are bimodally distributed into a group of non-responders whose responses are below $20 \%$ and a group of responders whose responses are higher. Figure 1(c) shows that a similar plot of the responses (absolute cpm) to cytomegalovirus in seropositive men gave a cut off level of $2500 \mathrm{cpm}$. The corresponding cut off level for responses to $P$ carinii was also $2500 \mathrm{cpm}$ (data not shown). No distinct bimodality was found for the absolute count of CD4 positive lymphocytes or for the CD4:CD8 ratio; accordingly, a value of $0.5 \times$ $10^{9} / 1$ was used as the cut off level for the absolute count of CD4 positive lymphocytes and $1.0 \times 10^{9} / 1$ as the cut off level for the CD4:CD8 ratio because these values are the lower limits of the normal range of the laboratory."

Figure 2 shows the correlation between clinical course and the initial immunological values. All values were significantly lower in the seropositive men than in the seronegative men, and the responses to pokeweed mitogen $(p<0.00006$, Mann-Whitney U test), phytohaemagglutinin $(p<0.014)$, and cytomegalovirus $(p<0.004)$, as well as the absolute count of CD4 positive lymphocytes $(p<0.016)$ and the CD4:CD8 ratio $(p<0.002)$, correlated significantly with the clinical course of disease in the seropositive men.

Table II shows the correlation for 34 seropositive men who did not have AIDS or AIDS related complex at the initial investigation. The initial response to pokeweed mitogen seemed to be the most accurate predictor of clinical course. Of 19 seropositive men whose response was greater than

a Relative response to pokeweed mitogen

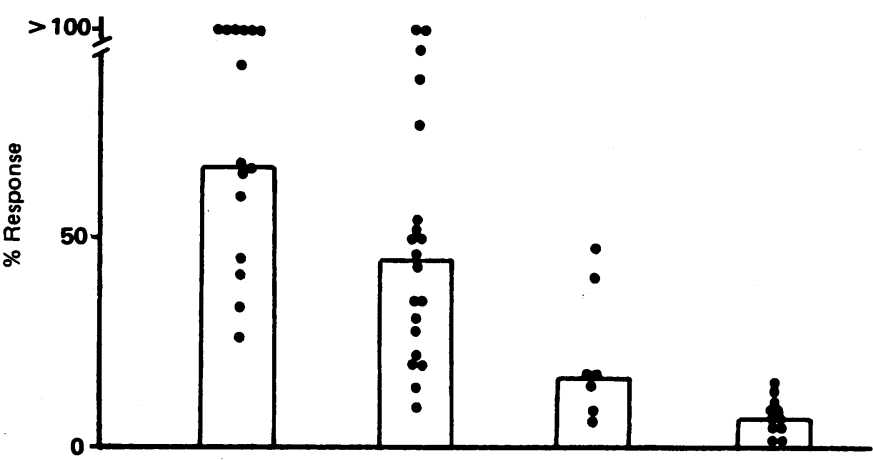

(b) Response to cytomegalovirus

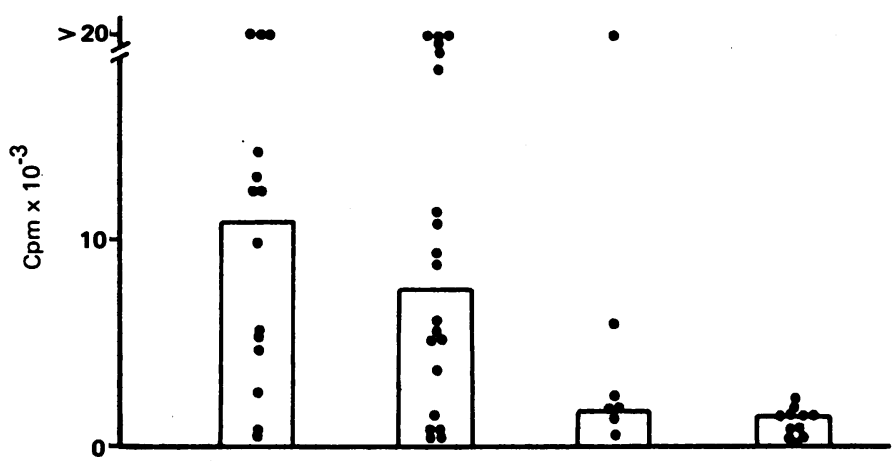

(c) Total No of $\mathrm{CD} 4$ positive cells

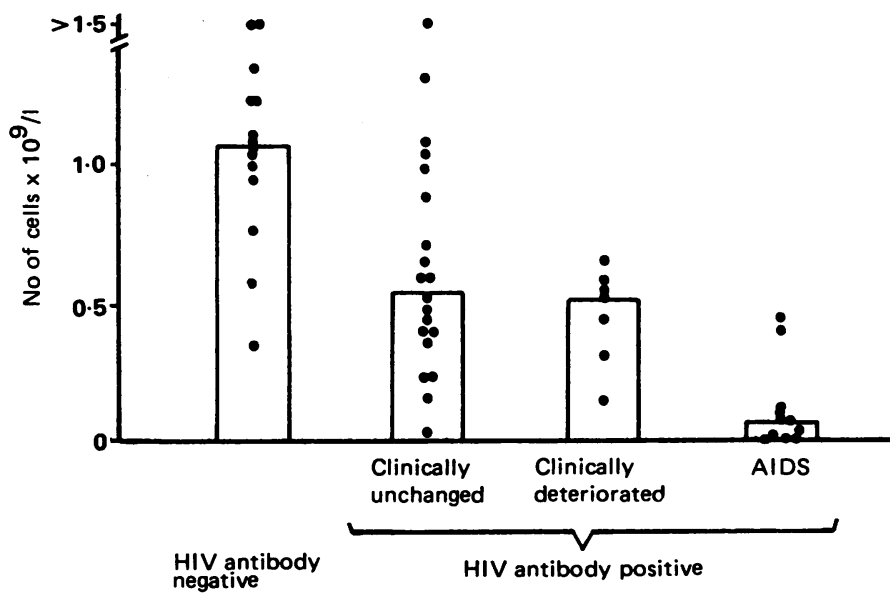

FIG 2-(a) Initial relative transformation response to pokeweed mitogen; (b) initial transformation response to cytomegalovirus; and (c) initial absolute counts of CD4 positive cells, correlated with later clinical condition. Values for the two men who had AIDS at start of study and who died during investigation are included in last column. 
$20 \%$, only two were in a worse clinical condition after one year, while among 15 whose response was less than $20 \% 13$ had a worsened clinical condition. Nine of these had developed AIDS, two of whom had died. The risk of a worse clinical condition was 55 times higher for men whose response to pokeweed mitogen was below $20 \%$ than for men whose response was higher. The response to cytomegalovirus also correlated well with the clinical course, with a relative risk of about.18. The absolute count of CD4 positive cells also had predictive properties but with a relative risk of only six.

\section{Discussion}

The clinical course of AIDS in the 34 seropositive men who did not initially have symptoms of AIDS or AIDS related complex and who were reinvestigated after one year could be correlated with the initial immunological values. In particular, a very strong correlation was found between a low relative response to pokeweed mitogen and a worsened clinical condition. The relative risk shows that seropositive men whose relative response to pokeweed mitogen is less than $20 \%$ have a 55 times higher risk of their clinical condition worsening than men whose response is higher. A similar correlation between the development of AIDS and low initial relative responses to pokeweed mitogen has been reported among homosexual men who have persistent lymphadenopathy ${ }^{8}$ while in a study that looked at absolute responses to pokeweed mitogen the accuracy of prediction was lower. ${ }^{5}$

Relative responses might be more accurate predictors, as the day to day variation has been eliminated. We do not know, however, why the response to pokeweed mitogen is reduced before the response to other mitogens. There is no marker for lymphocytes that can be stimulated by pokeweed mitogen, but pokeweed mitogen is known to stimulate about one third of lymphocytes whereas the stronger mitogens phytohaemagglutinin and con A stimulate up to $90 \%$. Pokeweed mitogen also stimulates immunoglobulin synthesis via the helper inducer cells (CD4 positive $2 \mathrm{H} 4$ negative), which in turn stimulate $B$ cells to produce immunoglobulin. ${ }^{12}$ We have shown that pokeweed mitogen stimulates both CD4 positive and CD8 positive lymphocytes in healthy controls and that both CD4 positive and CD8 positive lymphocytes in patients who have AIDS show a severely decreased response to pokeweed mitogen. ${ }^{13-15}$ The predictive value of the response to pokeweed mitogen might reflect the fact that pokeweed mitogen stimulates a subset of lymphocytes that have a regulatory function in the immune response.

The transformation response to the antigen cytomegalovirus also correlated with the clinical course of AIDS in this group, with a relative risk of 18 , but because responses to cytomegalovirus depend on previous exposure to the antigen the lack of response may be inconclusive. Other studies have reported a correlation between the development of AIDS and the absolute count of CD4 positive lymphocytes. ${ }^{6} 7$ This was confirmed in our study, but the relative risk for a worse clinical course was only six, and, in contrast with the relative response to pokeweed mitogen, the absolute count of CD4 positive lymphocytes did not correlate with a worsened clinical condition in patients who did not develop AIDS. As all of the patients were included because of an inverted CD4:CD8 ratio in a screening test before our investigation it is difficult to evaluate the relevance of this variable in our study.

Nine men in this study developed AIDS. This very high incidence is probably due to the criterion for inclusion in this investigation-namely, an inverted $\mathrm{CD} 4: \mathrm{CD} 8$ ratio. A prognostic factor for the development of AIDS among seropositive patients would be of great importance. Firstly, it might relieve the anxiety of many who are seropositive. Secondly, if in the future a treatment becomes available such a factor might indicate the patients to whom the treatment should be offered first.

The weaknesses of this study are that it was started before routine testing for HIV antibodies was possible and that the follow up was rather short. Thus it remains to be seen if the prognostic significance of a low response to pokeweed mitogen holds true for all seropositive patients and what the long term prognosis is for seropositive patients whose relative response to pokeweed mitogen is higher than $20 \%$. We conclude, however, that seropositive patients who have a decreased CD4:CD8 ratio and a low response to pokeweed mitogen have a rather poor short term prognosis.

We are especially grateful to Dr Bodil Norrild for giving us the herpes simplex antigen, to Dr Kertzel Andersen for the cytomegalovirus antigen, and to Dr Else Svejgaard for the Candida albicans antigen. BH was supported by the Danish Cancer Society (grant No 86-073). BØL was supported by the Danish Medical Research Council (grant Nos 12-5354 and 12-6033) and the Neye Foundation. The study was also supported by the Danish Medical Research Council and the Danish Haemophiliac Association.

\section{References}

1 Hofmann B, Platz P, Ødum N, et al. Occurrence of anti-HTLV-III antibodies in Danish high-risk homosexuals in 1982-83-seroconversion rate and risk of AIDS. AIDS Research 1986;2:1-3.

2 Centers for Disease Control. Update: acquired immunodeficiency syndrome in the San Francisco cohort study 1978-85. MMWR 1985;34:573.

3 Mann JM, Colebunders RL, Knonde N, et al. Natural history of human immunodeficiency virus infection in Zaire. Lancet 1986;ii:707-9.

4 Hofmann B, Ødum N, Plaz P, et al. Humoral responses to Pneumocystis carinii in patients with acquired immunodeficiency syndrome and in immunocompromised homosexual men. $\mathcal{I}$ Infect Dis 1985; 152:838-40.

5 Gold JWM, Weikel CS, Godbold J, et al. Unexplained persistent lymphadenopathy in homosexual men and the acquired immune deficiency syndrome. Medicine 1985;64:203-13.

6 Schwartz K, Visscher BR, Detels R, Taylor J, Nishanian P, Fahey J. Immunological changes in lymphadenopathy virus positive and negative symptomless male homosexuals: two years of observation. Lancet 1985; ii:831-2.

7 Weber JN, Wadsworth J, Rogers LA, et al. Three-year prospective study of HTLV-IIL/LAV infection in homosexual men. Lancet 1986; :1179-82.

8 Fishbein DB, Jonathan EK, Spira TJ, et al. Unexplained lymphadenopathy in homosexual men. JAMA 1985;254:930-5.

9 Wintrobe MM, Thom GW, Adams RD, et al, eds. Harrison's principles of internal medicine. Tokyo: McGraw-Hill, 1971.

10 Coffin J, Haase A, Levy JA, et al. Human immunodeficiency virus. Science 1986;232:697.

11 Lindhardt BØ, Ulrich K, Ryder LP, et al. HTLV-III antibody testing in three Danish blood banks. Vox Sang 1986;51(S1):9-14.

12 Morimoto C, Letvin LN, Boyd AW, et al. The isolation and characterization of the human helper inducer T cell subset. $\mathcal{F}$ Immuunol 1985;134:3762-9.

13 Hofmann B, Ødum N, Platz P, Ryder LP, Svejgaard A, Nielsen JO. Immunological studies in acquired immunodeficiency syndrome: functional studies of lymphocyte subpopulations. Scand f I mmunol 1985;21:235-43.

14 Hofmann B, Ødum N, Jakobsen BK, et al. Immunological studies in AIDS. II. Active suppression or intrinsic defect investigated by mixing AIDS cells with HLA-DR identical normal cells. Scand I I mmunol 1986;23:669-78.

15 Hofmann B, Ødum N, Fugger L, et al. Immunological studies in AIDS. Effect of TCGF and indomethacine on the in vitro lymphocyte response. Cancer Detect Prev (in press).

(Accepted 15 April 1987) 